\title{
Synthesis of 2-(2-Hydroxyethoxy)-3-hydroxysqualene and Characterization of Its Anti-Inflammatory Effects
}

\author{
Kazunori Sasaki, ${ }^{1,2,3,4}$ Yuri Inami, ${ }^{2,5}$ Kenichi Tominaga, ${ }^{2,3}$ Hideo Kigoshi, ${ }^{4}$ \\ Takashi Arimura $\mathbb{D}^{2,3}$ and Hiroko Isoda $\mathbb{D}^{1,2,6}$ \\ ${ }^{1}$ Alliance for Research on the Mediterranean and North Africa (ARENA), University of Tsukuba, 1-1-1 Tennodai, Tsukuba, \\ Ibaraki 305-8572, Japan \\ ${ }^{2}$ Open Innovation Laboratory for Food and Medicinal Resource Engineering, \\ National Institute of Advanced Industrial Science and Technology (AIST), University of Tsukuba, 1-1-1 Tennodai, Tsukuba, \\ Ibaraki 305-8572, Japan \\ ${ }^{3}$ Interdisciplinary Research Center for Catalytic Chemistry, \\ National Institute of Advanced Industrial Science and Technology (AIST), AIST Tsukuba Central 5-2, Tsukuba, \\ Ibaraki 305-8565, Japan \\ ${ }^{4}$ Faculty of Pure and Applied Sciences, University of Tsukuba, 1-1-1 Tennodai, Tsukuba, Ibaraki 305-8571, Japan \\ ${ }^{5}$ Graduate School of Pure and Applied Sciences, University of Tsukuba, Tsukuba, Ibaraki 305-8571, Japan \\ ${ }^{6}$ Faculty of Life and Environmental Sciences, University of Tsukuba, 1-1-1 Tennodai, Tsukuba, Ibaraki 305-8572, Japan
}

Correspondence should be addressed to Takashi Arimura; takashi-arimura@aist.go.jp and Hiroko Isoda; isoda.hiroko.ga@u.tsukuba.ac.jp

Received 4 October 2019; Revised 28 December 2019; Accepted 23 January 2020; Published 15 April 2020

Academic Editor: Paul M. Tulkens

Copyright ( 92020 Kazunori Sasaki et al. This is an open access article distributed under the Creative Commons Attribution License, which permits unrestricted use, distribution, and reproduction in any medium, provided the original work is properly cited.

Squalene (SQ), a natural precursor of many steroids, can inhibit tumor progression and decrease serum cholesterol levels. However, it is difficult to discern the effect of highly active molecules in the treatment of diseases because not enough active compounds reach the site of pathology in crowded biosystems. Therefore, it is necessary to design artificial probes that work effectively within crowded systems. In this study, to facilitate cell penetration, the ethylene glycol moiety (used as a probe) was chemically added to SQ to form 2-(2-hydroxyethoxy)-3-hydroxysqualene (HEHSQ). HEHSQ was prepared from 2,3-epoxysqualene and characterized by $\mathrm{R}_{\mathrm{f}}$, FT-IR, ${ }^{1} \mathrm{H}$ NMR, ${ }^{13} \mathrm{C}$ NMR, and high-resolution mass spectrometry. We then evaluated the anti-inflammatory effects of SQ and HEHSQ on lipopolysaccharide- (LPS-) stimulated RAW264.7 murine macrophages. To determine the effect of SQ and HEHSQ on the viability of RAW264.7 cells, an MTT assay was performed. To quantify the antiinflammatory effect of SQ and HEHSQ, we measured nitric oxide (NO) production, gene expression, and secretion of the proinflammatory cytokine tumor necrosis factor $\alpha$ (TNF- $\alpha$ ) and chemokine C-C motif chemokine 2 (CCL2) in LPS-stimulated RAW264.7 cells using an in vitro inflammatory model. 2,3-Epoxysqualene was prepared according to a reported methodology. The reaction of 2,3-epoxysqualene and ethylene glycol in 2-propanol produced 49\% HEHSQ. MTT results showed that 10 and $100 \mu \mathrm{g} / \mathrm{mL}$ HEHSQ treatment decreased cell viability, whereas SQ treatment $(1-100 \mu \mathrm{g} / \mathrm{mL})$ did not have any effect on viability. SQ $(100 \mu \mathrm{g} / \mathrm{mL})$ and HEHSQ $(1 \mu \mathrm{g} / \mathrm{mL})$ treatment significantly reduced the production of LPS-stimulated NO and decreased the expression and secretion of proinflammatory TNF- $\alpha$ and CCL2. Therefore, our results suggested that the anti-inflammatory effects of HEHSQ are 100 times higher than that of unmodified SQ. To the best of our knowledge, this study has demonstrated for the first time that HEHSQ can be potentially used as a safe alternative treatment to anti-inflammatory drugs. 


\section{Introduction}

Inflammation is a protective response against trauma, infection, and tissue injury [1]. Acute inflammation usually subsides in a short while. However, if acute inflammation persists or the agent causing the inflammation is not eliminated, then acute inflammation can progress to a chronic stage. Chronic inflammation is a long-term phenomenon, causing tissue destruction and organ dysfunction. Furthermore, chronic inflammation is associated with various diseases including atherosclerosis, cardiovascular diseases, and arthritis [2]. Chronic inflammation is considered an underlying cause of several diseases, and thus, it is important to prevent such inflammation. Macrophages play a critical role during inflammation. Following tissue injury or infection first, the responder macrophages are activated and exhibit an inflammatory phenotype [2]. Activated macrophages produce numerous inflammatory mediators, such as cytokines (tumor necrosis factor- $\alpha$ : TNF-a), chemokines (CCL2), and nitric oxide (NO), which are highly toxic for microorganisms and can also be harmful to surrounding healthy tissues and lead to aberrant inflammation [3, 4]. For example, excessive or chronic NO production reacts with superoxide anions to become peroxynitrite, which is a very aggressive-free radical species, leading to the induction of mitochondrial dysfunction and cytotoxicity of the surrounding tissues [5-7]. And CCL2, which belongs to the C-C class of chemokines, is a critical modulator of inflammation, regulating macrophage recruitment during wound healing, infections, and autoimmune diseases [8]. Therefore, chemokines are involved in a variety of inflammatory conditions, both acute and chronic [9]. Thus, modulation of macrophage activation could be a good strategy to prevent chronic inflammation. Today, nonsteroidal anti-inflammatory drugs (NSAIDs) are the most commonly prescribed drugs worldwide. These display anti-inflammatory and analgesic effects; however, longterm use of NSAIDs causes undesirable side effects including gastrointestinal irritation, high blood pressure, and liver problems [10]. Therefore, complementary medicine that has anti-inflammatory properties and is derived from natural products has gained attention.

Squalene (SQ), a natural precursor of many steroids, is so named because of its presence in shark liver oil. It is also prepared from the microalgae Aurantiochytrium [11]. Because it is not toxic to humans, SQ has been extensively used as a dietary supplement $[12,13]$, an adjuvant in therapeutic applications [14], and for alleviating oxidative stress [15]. Moreover, our previous study revealed that the high SQproducing microalgal strain (Aurantiochytrium) had an anti-inflammatory effect on lipopolysaccharide- (LPS-) stimulated mouse macrophage RAW264.7 cells in an in vitro inflammatory model [16]. Unfortunately, to date, attempts to improve the pharmacological effects of SQ have not met with much success. One of the factors limiting the pharmacological activity of SQ is its insolubility in polar solvents such as methanol, tetrahydrofuran, and dimethyl sulfoxide (DMSO); therefore, it cannot permeate cell membranes and reach tissues in a crowded environment.
In general, however, cells and tissues of living organisms make up a multimolecular system wherein diverse types of molecules get compartmentalized. Therefore, it is not often possible to use highly active molecules in the treatment of diseases, such as cancer, because enough active compounds cannot reach the site of pathology in crowded biosystems. Therefore, to improve pharmacological activity, artificial probes must be designed that effectively work within the crowded tissue architecture.

In the present study, we enhanced the pharmacological activity of SQ by increasing its bioavailability. The ethylene glycol moiety (used as a probe) was selectively introduced into SQ, creating HEHSQ, to facilitate tissue permeability. Also, we investigated the anti-inflammatory effect of SQ and HEHSQ on LPS-stimulated RAW264.7 murine macrophages.

\section{Materials and Methods}

2.1. Characterization of Squalene. All solvents used in the study were of reagent-grade quality and used without further purification unless otherwise noted. 2,3-Epoxysqualene was prepared according to a previously described methodology [17]. All column chromatography was undertaken using Merck silica gel 60 as the solid support.

HEHSQ was characterized by $\mathrm{R}_{\mathrm{f}}$, FT-IR, ${ }^{1} \mathrm{H} \mathrm{NMR},{ }^{13} \mathrm{C}$ NMR, and high-resolution mass spectrometry. The infrared (IR) spectrum was measured on a JASCO FT-IR-4100. NMR spectra were recorded on a Bruker Avance- 400 spectrometer operated at $400 \mathrm{MHz}$ and a JEOL RESONANCE ECX-100 spectrometer operated at $100 \mathrm{MHz}$ at room temperature $\left(20^{\circ} \mathrm{C}\right)$ in the Fourier transform mode. ${ }^{1} \mathrm{H}$ NMR spectra were reported in $\delta$ units, parts per million (ppm), and calibrated relative to the signal for residual chloroform $(7.26 \mathrm{ppm})$ in chloroform- $\mathrm{d}_{1}\left(\mathrm{CDCl}_{3}\right) .{ }^{13} \mathrm{C} \mathrm{NMR}$ data were reported in ppm relative to $\mathrm{CDCl}_{3}(77.16 \mathrm{ppm})$ and obtained with $1 \mathrm{H}$ decoupling. High-resolution mass spectrometric analyses were undertaken using an electrospray ionization time of flight based as a reserpine $(\mathrm{m} / z 609.2812)$ matrix on a JEOL JMS-100CS instrument.

2.2. Sample Preparation for In Vitro Study. SQ was purchased from Fujifilm Wako Co, Ltd. (Tokyo, Japan). SQ and HEHSQ were dissolved in DMSO to obtain the respective stock solutions, which were then diluted in cell culture medium for the in vitro experiment.

2.3. Preparation of LPS. LPS (Escherichia coli O111:B4) was purchased from EMD Millipore Co. (Billerica, MA, USA). A total of $5 \mathrm{mg}$ of LPS was dissolved in $2 \mathrm{~mL}$ of phosphatebuffered saline without divalent cations (PBS (-)) and stored at $-80^{\circ} \mathrm{C}$ in the dark until subsequent use.

2.4. Culture of RAW264.7 Cells. Murine macrophage-like RAW264.7 cells were purchased from RIKEN BioResource Center (RCB0535, RIKEN BRC, Tsukuba, Japan). RAW264.7 cells were cultured in Dulbecco's modified Eagle medium supplemented with $10 \%$ heat-inactivated fetal 
bovine serum and penicillin-streptomycin at $37^{\circ} \mathrm{C}$ in a humidified incubator containing $5 \% \mathrm{CO}_{2}$. Cells were seeded onto 96-well plates at a density of $2.0 \times 10^{5}$ cells per well and were incubated at $37^{\circ} \mathrm{C}$ for $24 \mathrm{~h}$.

2.5. 3-(4,5-Dimethylthiazol-2-yl)-2,5-diphenyltetrazolium Bromide (MTT) Assay. Cell viability and mitochondrial activity were determined using the MTT assay to check the cytotoxicity of SQ $(1,10$, and $100 \mu \mathrm{g} / \mathrm{mL})$ and HEHSQ $(1,10$, and $100 \mu \mathrm{g} / \mathrm{mL})$. RAW264.7 cells were seeded at $2 \times 10^{5}$ cells $/ \mathrm{mL}$ in 96-well plates (BD BioCoat, USA) and incubated for $24 \mathrm{~h}$. Then, the cells were treated with SQ or HEHSQ for $24 \mathrm{~h}$. A solution of $5 \mathrm{mg} / \mathrm{mL}$ MTT dissolved in PBS was added $(10 \mu \mathrm{L} /$ well $)$ and incubated for another $24 \mathrm{~h}$. The resulting MTT formazan was dissolved in $100 \mu \mathrm{L}$ of $10 \%$ sodium dodecyl sulfate $(\mathrm{w} / \mathrm{v})$, and the absorbance was measured using a microtiter plate reader (Dainippon Sumitomo Pharma Co., Ltd., Japan). The absorbance values were normalized to that of the culture medium, and viability was calculated as a percentage (\%) of the untreated cells.

2.6. Measurement of NO Production. To evaluate the effect of SQ and HEHSQ on NO production in LPS-stimulated RAW264.7 cells, the Griess reaction was used following the methodology described in a previous study [16]. Briefly, RAW264.7 cells were seeded at $2 \times 10^{5}$ cells/mL in 96 -well plates (BD BioCoat) and incubated for $24 \mathrm{~h}$. The cells were treated with SQ $(1,10$, and $100 \mu \mathrm{g} / \mathrm{mL})$ or $\operatorname{HEHSQ}(1,10$, and $100 \mu \mathrm{g} / \mathrm{mL})$ at $37^{\circ} \mathrm{C}$ for $24 \mathrm{~h}$. After the treatment, LPS solution (final concentration: $1 \mu \mathrm{g} / \mathrm{mL}$ ) was added to each well and incubated for $12 \mathrm{~h}$ at $37^{\circ} \mathrm{C}$. Then, the cell supernatant was mixed at a 1:1 ratio with the Griess reagent (1\% sulfanilic acid and $0.1 \% \mathrm{~N}$-(1-naphthyl) ethylene diamine dihydrochloride in $2.5 \%$ phosphoric acid). After $10 \mathrm{~min}$ incubation in the dark, the absorbance was measured at $540 \mathrm{~nm}$ using a microtiter plate reader (Dainippon Sumitomo Pharma Co., Ltd., Japan), and nitrite concentration was determined by dilution of sodium nitrite $\left(\mathrm{NaNO}_{2}\right.$, Fujifilm Wako Co, Ltd., Tokyo, Japan) as a standard.

2.7. RNA Isolation from RAW264.7 Cells. RAW264.7 cells were seeded at $3.7 \times 10^{5}$ cells $/ \mathrm{mL}$ in a $10 \mathrm{~cm}^{2}$ dish (BD BioCoat) and incubated at $37^{\circ} \mathrm{C}$ for $24 \mathrm{~h}$. The RAW264.7 cells were then treated with SQ $(100 \mu \mathrm{g} / \mathrm{mL})$ or HEHSQ $(1 \mu \mathrm{g} / \mathrm{mL})$ at $37^{\circ} \mathrm{C}$ for $24 \mathrm{~h}$. After the treatment, LPS solution (final concentration: $1 \mu \mathrm{g} / \mathrm{mL}$ ) was added to each well and incubated for a further $12 \mathrm{~h}$ at $37^{\circ} \mathrm{C}$. Total RNA was isolated using ISOGEN (Nippon Gene, Tokyo, Japan) following the manufacturer's instructions as per a previous study [16].

2.8. Measurement of Proinflammatory Cytokine and Chemokine Using Real-Time Reverse Transcription Polymerase Chain Reaction (RT-PCR). Real-time RT-PCR was performed to evaluate the effect of SQ or HEHSQ on proinflammatory cytokine and chemokine expression in RAW264.7 cells. The TaqMan probe (Thermo Fisher Scientific, USA) was used for the quantification of gene expression. Using a superscript III reverse transcriptase kit (Thermo Fisher Scientific), a complementary DNA (cDNA) solution was synthesized following the manufacturer's instructions. For quantification of transcript amounts, TaqMan real-time RT-PCR amplification reactions were performed using the Applied Biosystems 7500 Fast RealTime System (Thermo Fisher Scientific). All primer sets and the TaqMan Universal PCR Master Mix were obtained from Thermo Fisher Scientific. Specific primers for actin beta (Mm02619580_g1), tumor necrosis factor $\alpha$ (TNF- $\alpha)$ (Mm00443258_m1), C-C motif chemokine 2 (CCL2) (Mm00441242_m1), and iNOS (Mm00440502_m1) were used.

2.9. Enzyme-Linked Immunosorbent Assay (ELISA) to Measure TNF- $\alpha$ and CCL2. The effects of SQ or HEHSQ on cytokine production in RAW 264.7 cells were determined by ELISA. In the assay, cells $\left(3.7 \times 10^{5}\right.$ cells $\left./ \mathrm{mL}\right)$ were seeded in a $10 \mathrm{~cm}^{2}$ dish (BD BioCoat) and treated with SQ $(100 \mu \mathrm{g} / \mathrm{mL})$ or HEHSQ $(1 \mu \mathrm{g} / \mathrm{mL})$ at $37^{\circ} \mathrm{C}$ for $24 \mathrm{~h}$. After the treatment, LPS solution (final concentration: $1 \mu \mathrm{g} / \mathrm{mL}$ ) was added to each well and incubated for $12 \mathrm{~h}$ at $37^{\circ} \mathrm{C}$. The cell supernatants were collected by centrifugation at $1000 \times g$ for $5 \mathrm{~min}$, and the levels of TNF- $\alpha$ and CCL2 were determined using commercial ELISA kits (Proteintech Group, Japan) according to the manufacturer's instructions.

2.10. Statistical Analysis. All results are expressed as mean \pm standard deviation (SD), and statistical evaluation was performed using the one-way ANOVA followed by post hoc Ryan-Einot-Gabriel-Welsch multiple range test. Differences were considered statistically significant when the $P$ value was less than 0.05 .

\section{Results}

3.1. Preparation and Identification of 2-(2-Hydroxyethoxy)-3hydroxysqualene. 2,3-Epoxysqualene (Figure 1(a)) (31 mg, $71 \mathrm{mmol})$ and ethylene glycol $(2.4 \mathrm{~mL}, 43 \mathrm{mmol})$ were dissolved in 2-propanol $(9.6 \mathrm{~mL})$. The mixture was heated to $80^{\circ} \mathrm{C}$ for $6 \mathrm{~h}$ while being stirred and then cooled to room temperature. $\mathrm{H}_{2} \mathrm{O}(15 \mathrm{~mL})$ and ethyl acetate $(30 \mathrm{~mL})$ were added, and the organic layer washed with saturated brine and $\mathrm{H}_{2} \mathrm{O}$ and dried over $\mathrm{Na}_{2} \mathrm{SO}_{4}$. The solvent was evaporated following column chromatography on silica gel, eluting with hexane:ethyl acetate $(5: 1)$ produced HEHSQ (Figure 1(b)) $(17 \mathrm{mg}, 49 \%)$ as a colorless oil.

$R_{f}=0.08$ (hexane:ethyl acetate $=4: 1$ ).

IR $\left(\mathrm{CHCl}_{3}\right): 3451,2977,2932,2877,1452,1381,1219$, $1083,909,670 \mathrm{~cm}^{-1}$.

${ }^{1} \mathrm{H} \mathrm{NMR}\left(400 \mathrm{MHz}, \mathrm{CDCl}_{3}\right): \delta 5.20-5.08(\mathrm{~m}, 5 \mathrm{H})$, 3.75-3.68 (m, 2H), 3.55-3.46 (m, 3H), $2.29(\mathrm{~m}, 1 \mathrm{H})$, 2.12-1.95 (m, 16H), $1.68(\mathrm{~s}, 3 \mathrm{H}), 1.62(\mathrm{~s}, 3 \mathrm{H}), 1.60$ (br s, $12 \mathrm{H}), 1.52-1.37$ (m, 5H), $1.15(\mathrm{~s}, 3 \mathrm{H}), 1.14(\mathrm{~s}, 3 \mathrm{H}) \mathrm{ppm}$.

${ }^{13} \mathrm{C} \mathrm{NMR}\left(100 \mathrm{MHz}, \mathrm{CDCl}_{3}\right): \delta 135.1,135.1,134.9$, 134.8, 131.2, 124.7, 124.4, 124.3, 124.3 (2C), 77.8, 76.0, 


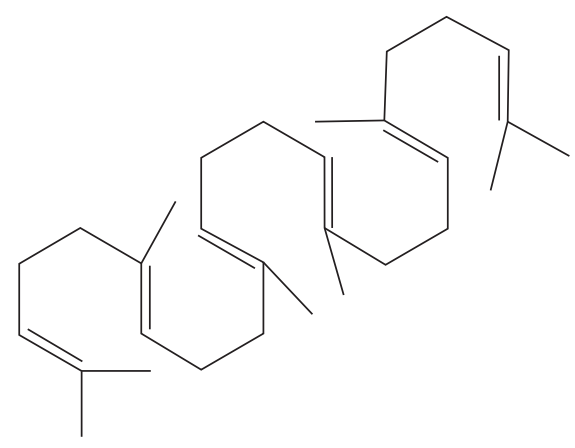

(a)

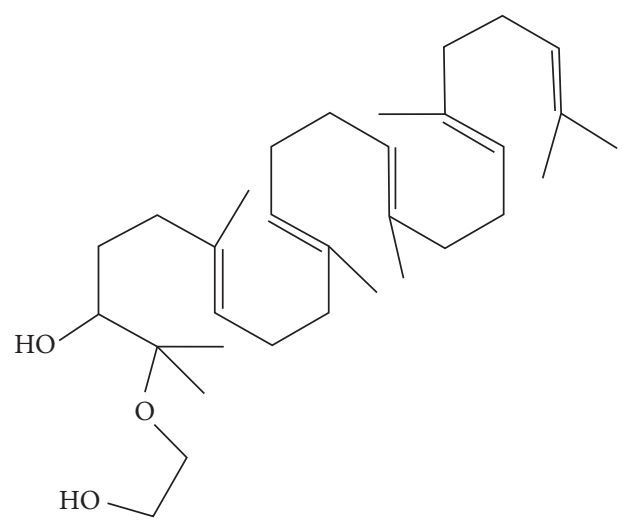

(b)

Figure 1: Structure of (a) 2,3-epoxysqualene and (b) 2-(2-hydroxyethoxy)-3-hydroxysqualene.

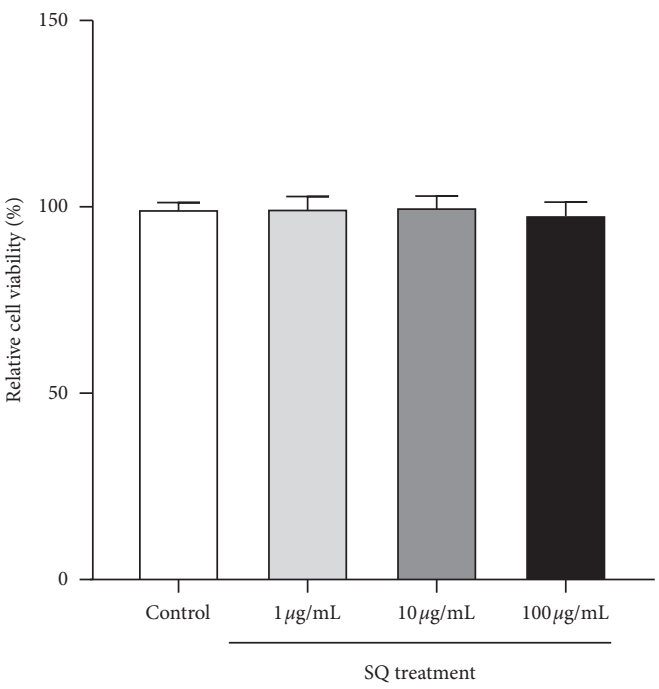

(a)

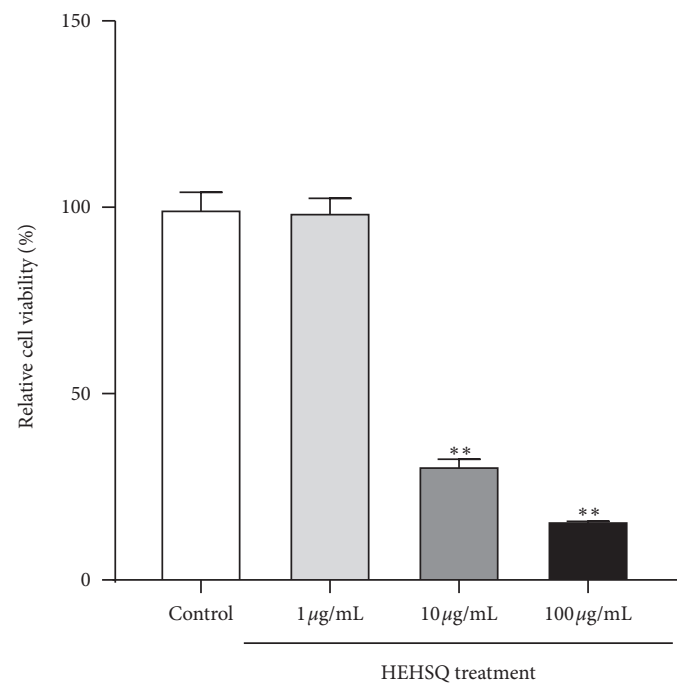

(b)

Figure 2: Effects of (a) squalene (SQ) and (b) 2-(2-hydroxyethoxy)-3-hydroxysqualene (HEHSQ) on the viability of RAW264.7 cells. RAW264.7 cells were treated with SQ or HEHSQ at 1, 10, and $100 \mu \mathrm{g} / \mathrm{mL}$ for $24 \mathrm{~h}$. Cell viability was measured by MTT assay. Values are expressed as the mean \pm SD of triplicate experiments and are expressed relative to the percentage of control. The mean value that is significantly different from that of the control group is indicated as ${ }^{* *} P<0.01$.

$62.4,62.2,39.7,39.7(2 \mathrm{C}), 36.8,29.7,28.6(2 \mathrm{C}), 26.7$, 26.7, 26.6, 25.7, 21.6, 19.8, 17.7, 16.0 (3C), 16.0 ppm.

HRMS (ESI): $m / z 511.4131$ (calculated for $\mathrm{C}_{32} \mathrm{H}_{56} \mathrm{NaO}_{3}$ $[\mathrm{M}+\mathrm{Na}]^{+}$511.4127, $\left.\Delta+0.4 \mathrm{mmu}\right)$.

3.2. Cytotoxic Effect of Squalene and 2-(2-Hydroxyethoxy)-3hydroxysqualene on RAW264.7 Cells. To evaluate the cytotoxicity of SQ and HEHSQ, RAW264.7 cells were treated with SQ $(1,10$, and $100 \mu \mathrm{g} / \mathrm{mL})$ or HEHSQ $(1,10$, and $100 \mu \mathrm{g} / \mathrm{mL}$ ) for $24 \mathrm{~h}$ and cell viability was measured using the MTT assay. None of the SQ concentrations tested nor the $1 \mu \mathrm{g} / \mathrm{mL}$ HEHSQ-treated cells showed any cytotoxic effects (Figures 2(a) and 2(b), respectively). Moreover, we also found that $1 \%$ DMSO- $(100 \mu \mathrm{g} / \mathrm{mL})$ treated RAW264.7 cells showed no reduction of cell viability (Supplementary figure S1). However, 10 and $100 \mu \mathrm{g} / \mathrm{mL}$ of HEHSQ treatments showed a significant $(P<0.01)$ reduction in cell viability by $31.2 \pm 1.3 \%$ and $16.5 \pm 0.3 \%$, respectively, compared with the untreated group (Figure 2(b)).

3.3. Effect of Squalene and 2-(2-Hydroxyethoxy)-3-hydroxysqualene on NO Production in LPS-Treated RAW264.7 Cells. $\mathrm{NO}$, a chemical mediator produced by damaged tissues and inflammatory cells, is a part of a group of unstable radical moieties known as reactive oxygen species [18] and is one of the most important factors in the immune system [19]. In the present study, the effects of SQ and HEHSQ on NO production in LPS-stimulated RAW264.7 cells were evaluated. LPS- $(1 \mu \mathrm{g} / \mathrm{mL})$ treated RAW264.7 cells showed the highest increase in NO production compared with the control cells. The treatment with SQ $(100 \mu \mathrm{g} / \mathrm{mL})$ for $24 \mathrm{~h}$ significantly reduced LPS-stimulated NO production by 


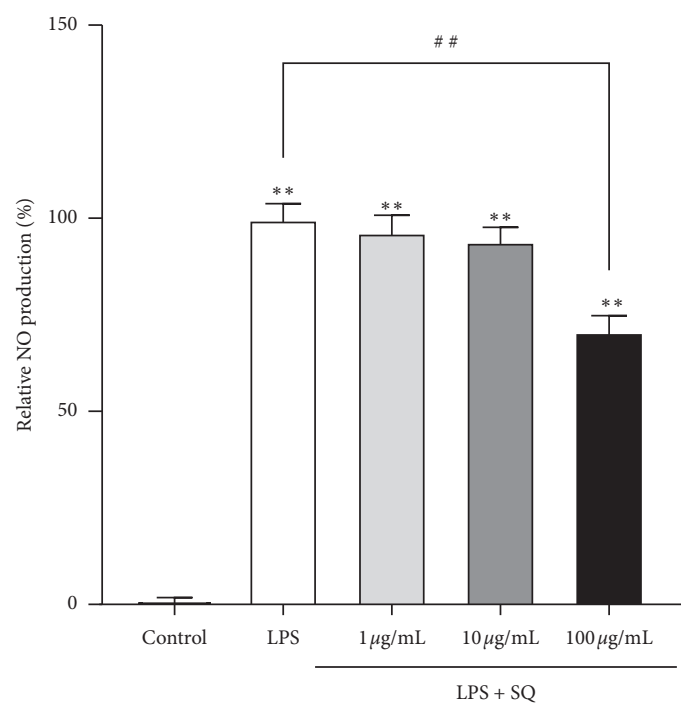

(a)

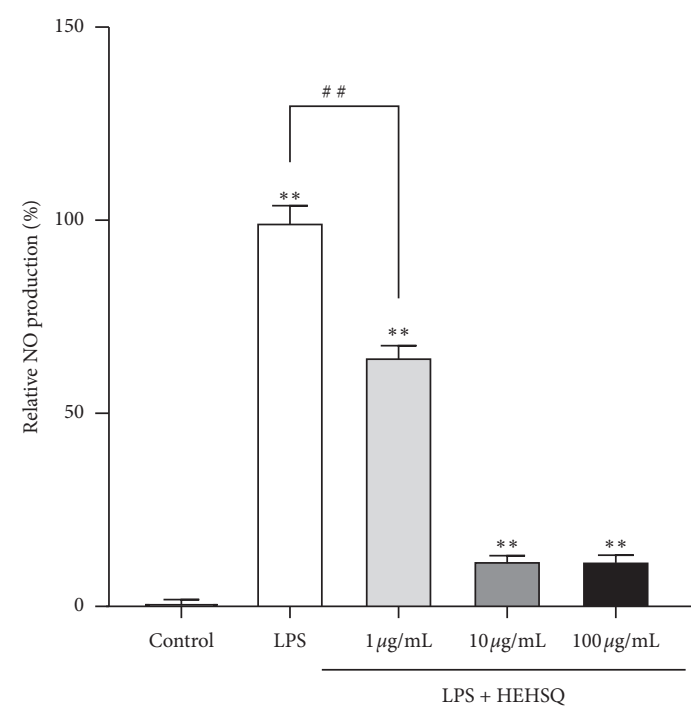

(b)

FIGURE 3: Effects of (a) squalene (SQ) and (b) 2-(2-hydroxyethoxy)-3-hydroxysqualene (HEHSQ) on LPS-stimulated NO production in RAW264.7 cells. Cells were treated with SQ or HEHSQ at 1, 10, and $100 \mu \mathrm{g} / \mathrm{mL}$ for $24 \mathrm{~h}$. Subsequently, cells were activated with LPS $(1 \mu \mathrm{g} / \mathrm{mL})$ for $12 \mathrm{~h}$. The amount of NO production was measured by the Griess reaction. Values are expressed as the mean \pm SD of triplicate experiments and are expressed relative to the percentage of control LPS (-). The mean value that is significantly different from that of the control LPS $(-)$ group is indicated as ${ }^{* *} P<0.01$. The mean value that is significantly different from that of the control LPS $(+)$ group is indicated as ${ }^{\#} P<0.01$.

approximately $30 \%$, although 1 and $10 \mu \mathrm{g} / \mathrm{mL}$ of SQ-treated cells did not show any significant change (Figure 3(a)). The $1 \mu \mathrm{g} / \mathrm{mL}$ of HEHSQ-treated cells showed a significant reduction in NO production by approximately $35 \%$ compared with the LPS-stimulated cells (Figure 3(b)). Additionally, 10 and $100 \mu \mathrm{g} / \mathrm{mL}$ HEHSQ-treated cells showed a significant decrease in NO production. However, this effect was most likely due to a decrease in cell viability. On the other hand, $1 \%$ DMSO- $(100 \mu \mathrm{g} / \mathrm{mL})$ treated RAW264.7 cells did not show any reduction of NO production compared with the LPS-stimulated cells (Supplementary Figure S2).

3.4. Effect of Squalene and 2-(2-Hydroxyethoxy)-3-hydroxysqualene on Proinflammatory Cytokine and Chemokine Production in LPS-Treated RAW264.7 Cells. Proinflammatory cytokines and chemokines are mainly produced by activated macrophages and are involved in the modulation of the inflammatory reaction [20]. Although proinflammatory cytokines and chemokines are required as a defense mechanism for our body, the overproduction of proinflammatory cytokines can damage tissues and cause an abnormal immune response [4]. Thus, the regulation of proinflammatory cytokines, in turn, contributes to modulating excessive inflammatory responses. In the present study, to evaluate the effects of SQ and HEHSQ on LPS-stimulated inflammatory cytokine and chemokine production, TNF- $\alpha$, CCL2, and iNOS gene expressions were measured by real-time RT-PCR. RAW264.7 cells were treated with $100 \mu \mathrm{g} / \mathrm{mL}$ of SQ or $1 \mu \mathrm{g} /$ $\mathrm{mL}$ of HEHSQ for $24 \mathrm{~h}$. After the treatment, RAW264.7 cells were stimulated with LPS for $12 \mathrm{~h}$. The $100 \mu \mathrm{g} / \mathrm{mL}$ of SQ- treated cells showed significantly lower $(P<0.01)$ TNF- $\alpha$ gene expression by approximately 50\% (Figure 4(a)), CCL2 (Figure 4(b)) gene expression by approximately $80 \%$, and iNOS (Figure 4(c)) gene expression by approximately $60 \%$ than that in LPS-stimulated RAW264.7 cells. The $1 \mu \mathrm{g} / \mathrm{mL}$ of HEHSQ-treated cells also showed a significantly lower gene expressions of TNF- $\alpha$ by approximately $65 \%$ (Figure $4(\mathrm{a})$ ), CCL2 (Figure 4(b)) by approximately $80 \%$, and iNOS (Figure 4(c)) by approximately $70 \%$ than that in LPSstimulated RAW264.7 cells. On the other hand, 1\% DMSO$(100 \mu \mathrm{g} / \mathrm{mL})$ treated RAW264.7 cells did not show any reduction of gene expression of TNF- $\alpha$ (Supplementary Figure S3A) and CCL2 (Supplementary Figure S3B) compared with the LPS-stimulated cells.

3.5. Effect of Squalene and 2-(2-Hydroxyethoxy)-3-hydroxysqualene on Proinflammatory Cytokine and Chemokine Secretion in LPS-Treated RAW264.7 Cells. ELISA assays were performed to quantify TNF- $\alpha$ and CCL2 secretion in the medium of RAW264.7 cells to confirm whether SQ or HEHSQ could regulate the inflammation in RAW264.7 cells. The MTT assay and NO assay showed that the optimal dose of SQ and HEHSQ were 100 and $1 \mu \mathrm{g} / \mathrm{mL}$, respectively. As shown in Figure 5, LPS-induced cells secreted significantly more TNF- $\alpha \quad(770.7 \pm 24.4 \mu \mathrm{g} / \mathrm{mL})$ and CCL2 $(765.6 \pm 19.8 \mu \mathrm{g} / \mathrm{mL})$ into the culture medium than untreated cells $(351.4 \pm 10.5 \mu \mathrm{g} / \mathrm{mL}$ and $314.0 \pm 26.1 \mu \mathrm{g} / \mathrm{mL}$, respectively). However, $100 \mu \mathrm{g} / \mathrm{mL}$ SQ $(675.2 \pm 35.3 \mu \mathrm{g} / \mathrm{mL})$ or $1 \mu \mathrm{g} / \mathrm{mL}$ HEHSQ $(490.4 \pm 18.0 \mu \mathrm{g} / \mathrm{mL})$-treated cells showed significantly lower $(P<0.01)$ TNF- $\alpha$ levels than that of the LPS-stimulated RAW264.7 cells (Figure 5(a)). 


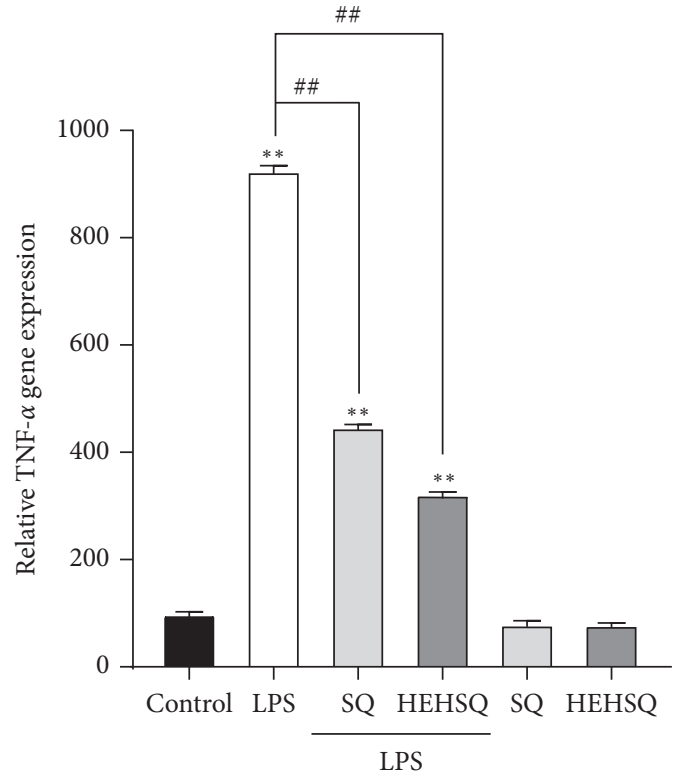

(a)

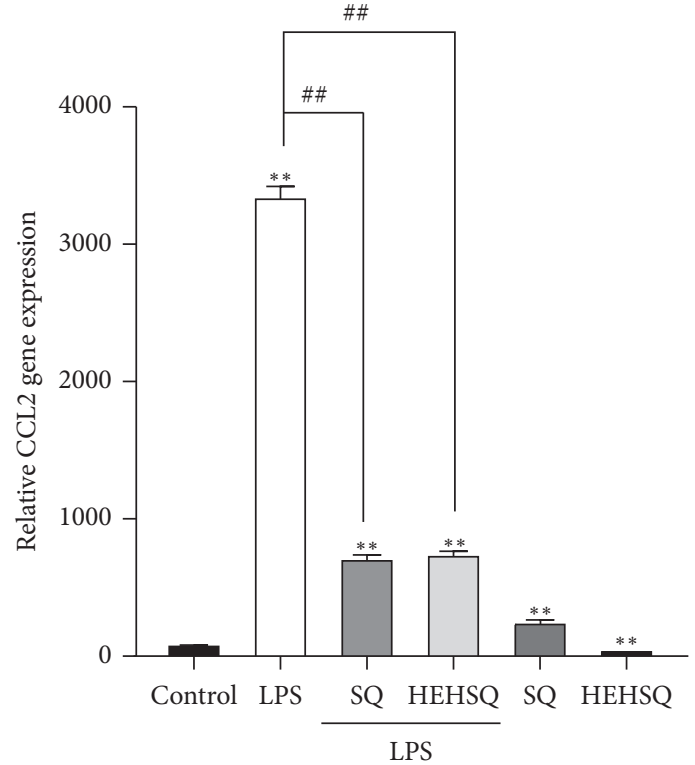

(b)

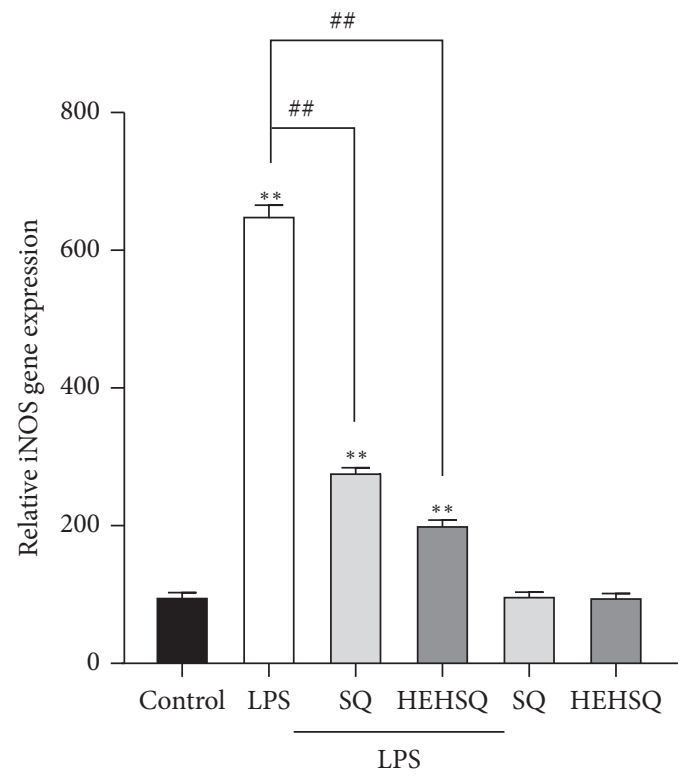

(c)

FIGURE 4: Effects of squalene (SQ) and 2-(2-hydroxyethoxy)-3-hydroxysqualene (HEHSQ) on gene expressions of (a) TNF- $\alpha$, (b) CCL2, and (c) iNOS in RAW264.7 cells. RAW264.7 cells were treated with $100 \mu \mathrm{g} / \mathrm{mL}$ SQ or $1 \mu \mathrm{g} / \mathrm{mL}$ HEHSQ for 24 h. Following that, cells were activated with LPS $(1 \mu \mathrm{g} / \mathrm{mL})$ for $12 \mathrm{~h}$. After activation, the gene expressions of TNF- $\alpha$, CCL2, and iNOS were evaluated using real-time RTPCR. Values are expressed as the mean \pm SD of triplicate experiments and are expressed relative to the percentage of control LPS (-). The mean value that is significantly different from that of the control LPS $(-)$ group is indicated as ${ }^{* *} P<0.01$. The mean value that is significantly different from that of the control LPS (+) group is indicated as ${ }^{\# \#} P<0.01$.

Moreover, $100 \mu \mathrm{g} / \mathrm{mL}$ SQ $(558.0 \pm 63.6 \mu \mathrm{g} / \mathrm{mL})$ - or $1 \mu \mathrm{g} / \mathrm{mL}$ HEHSQ $(524.7 \pm 45.8 \mu \mathrm{g} / \mathrm{mL})$-treated cells also inhibited CCL2 levels (Figure 5(b)).

\section{Discussion}

SQ, a biosynthesized triterpene hydrocarbon and a precursor for all steroids in animals and plants, is frequently used in the pharmaceutical and medical industries because it has several beneficial physiological effects such as the enhanced immune function, reduced serum cholesterol levels, protection from gamma rays, and suppression of tumor growth [12, 21-23]. In the present study, a molecular design was created to enhance the pharmacological activity of SQ in a crowded cellular environment. The introduction of the ethylene glycol moiety as a probe at the 2-position of SQ allows it to penetrate biological tissues because HEHSQ is highly soluble in methanol, tetrahydrofuran, and 


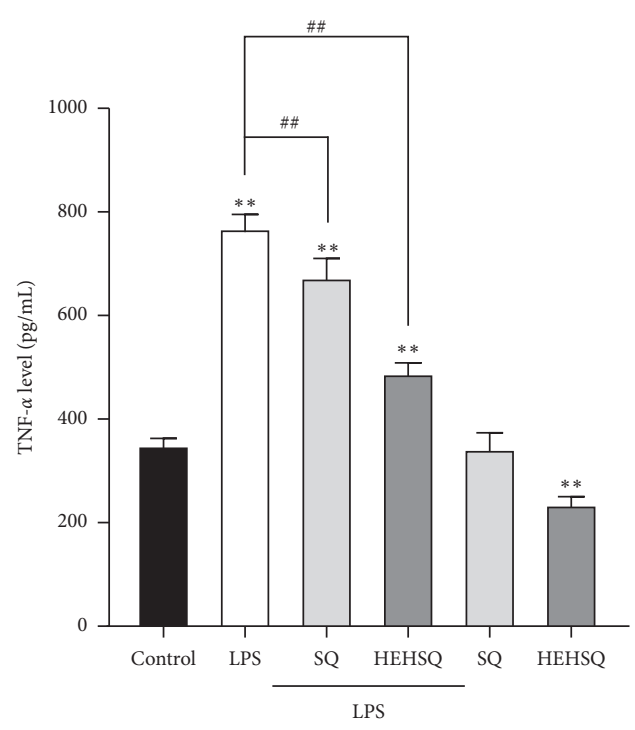

(a)

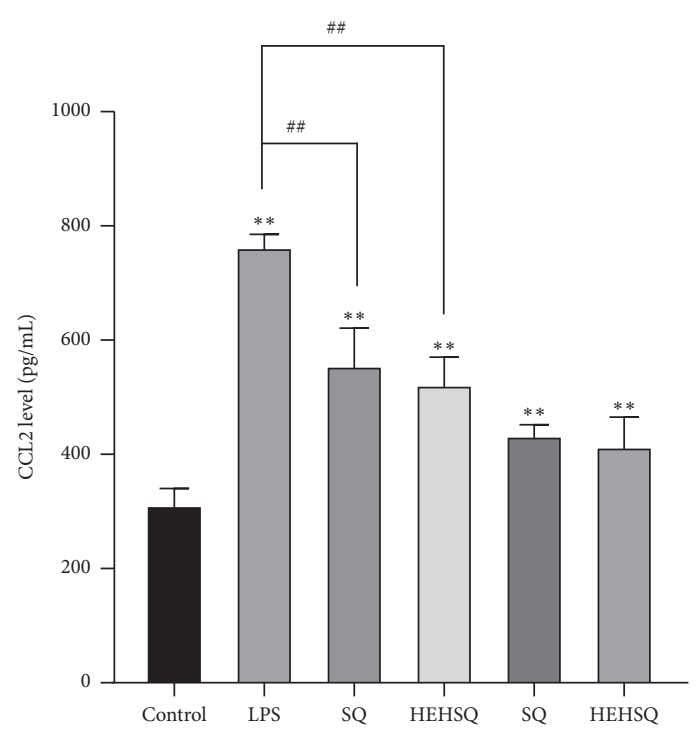

(b)

FIGURE 5: Effects of squalene (SQ) and 2-(2-hydroxyethoxy)-3-hydroxysqualene (HEHSQ) on the production TNF- $\alpha$ (a) and CCL2 (b) in RAW264.7 cells. RAW264.7 cells were treated with $100 \mu \mathrm{g} / \mathrm{mL}$ SQ or $1 \mu \mathrm{g} / \mathrm{mL}$ HEHSQ for $24 \mathrm{~h}$. Following that, cells were activated with LPS $(1 \mu \mathrm{g} / \mathrm{mL})$ for $12 \mathrm{~h}$. After activation, the levels of TNF- $\alpha$ and CCL2 in the culture supernatant were evaluated using ELISA assays. Values are expressed as the mean \pm SD of triplicate experiments and are expressed relative to the percentage of control LPS (-). The mean value that is significantly different from that of the control LPS (-) group is indicated as ${ }^{* *} P<0.01$. The mean value that is significantly different from that of the control LPS (+) group is indicated as ${ }^{\# \#} P<0.01$.

dimethyl sulfoxide, which are miscible with water. As to the preparative quantity of HEHSQ in the synthetic procedure from 2,3-epoxysqualene, it gives a small amount of HEHSQ, $17 \mathrm{mg}$ (49\% yield). However, in the future study, we plan to improve the synthetic method that can be used to prepare quantities up to around $2000 \mathrm{mg}$ at a time in a 1liter flask.

First, in the in vitro study, an MTT assay was performed to evaluate the cytotoxicity of SQ and HEHSQ. The MTT assay results showed that the 1 to $100 \mu \mathrm{g} / \mathrm{mL}$ SQ treatment did not change the cell viability, thus suggesting that it may be difficult for SQ to enter cells. However, the HEHSQ treatment showed a significant decrease in cell viability at 10 and $100 \mu \mathrm{g} / \mathrm{mL}$ concentrations. These results suggest that the addition of ethylene glycol to SQ, creating HEHSQ, increased the bioavailability of SQ.

In the present study, we evaluated the anti-inflammatory effects of SQ and HEHSQ on LPS-stimulated RAW cells in an in vitro inflammatory model. LPS triggers several inflammatory reactions by binding to its specific receptor, tolllike receptor 4 (TLR4) in macrophages [24], and hence, it is widely used as an inflammatory stimulator. Once LPS binds to TLR4, several downstream signaling pathways are activated, resulting in the production of inflammatory substances including proinflammatory cytokines and NO. Normally, NO is known to exert different actions in various biological processes, including immune defense response and inflammation [5]. In the present study, we found that LPStreated RAW264.7 cells increased NO production. Although low concentrations of SQ $(1$ and $10 \mu \mathrm{g} / \mathrm{mL})$ did not affect NO production, high SQ concentration $(100 \mu \mathrm{g} / \mathrm{mL})$ showed lower NO production than that of the LPS-stimulated RAW cells. Additionally, NO production in RAW cells treated with low concentration HEHSQ $(1 \mu \mathrm{g} / \mathrm{mL})$ was significantly lower than that in the LPS-stimulated RAW cells.

TNF- $\alpha$, one of the major proinflammatory cytokines, is released from macrophages in response to inflammation and induces vasodilation and loss of vascular permeability, which facilitates immune cell infiltration including lymphocytes, neutrophils, and monocytes [25]. TNF- $\alpha$ helps recruit immune cells into sites of inflammation and hence promotes inflammatory responses. It has been reported previously that excess amounts of TNF- $\alpha$ play a pathological role in several diseases including inflammatory bowel diseases, rheumatoid arthritis, and asthma [25]. Similar to cytokines, the chemokines (e.g., CCL2) play key roles in the inflammation process [26]. Chemokines, a family of small soluble proteins that regulate cell migration via the formation of concentration gradients, exhibit a high degree of conservation between mice and humans and have long been recognized as critical mediators of immune cell trafficking during embryonic development, wound healing, and infection [27-29]. Thus, regulating the production of inflammatory mediators, such as TNF- $\alpha$ and CCL2, contributes to an anti-inflammatory effect. Moreover, preventing overproduction of inflammatory mediators shifts the balance towards the beneficial effects of chronic inflammation, and it may prevent several diseases. In the present study, the effect of SQ and HEHSQ on TNF- $\alpha$, CCL2, and iNOS gene expressions (production) and TNF- $\alpha$ and CCL2 levels in the culture supernatant (secretion) were evaluated using LPS-stimulated RAW264.7 cells. Our results showed that LPS treatment significantly increased the expressions of TNF- $\alpha$, CCL2, and iNOS compared with untreated RAW264.7 cells. Moreover, TNF- $\alpha$ and CCL2 levels in the 
culture supernatant of LPS-treated cells were also higher than that of untreated cells. However, SQ $(100 \mu \mathrm{g} / \mathrm{mL})$ and HEHSQ $(1 \mu \mathrm{g} / \mathrm{mL})$ treatments significantly lowered the expression and secretion of TNF- $\alpha$ and CCL2 upon LPS stimulation. Therefore, our results indicated that the ethylene glycol modification (HEHSQ) enhanced the anti-inflammatory effect of SQ by 100 fold compared with unmodified SQ. Our results suggest that HEHSQ, which shows anti-inflammatory properties at low concentrations ( $1 / 100$ concentration of $S Q)$, could be used in dietary supplements, cosmetics, and functional foods for the prevention and treatment of chronic inflammatory diseases.

In this study, we have uncovered the anti-inflammatory effects of HEHSQ; however, the underlying molecular mechanism effect remains unclear. We used LPS-stimulated RAW264.7 cells to evaluate the anti-inflammatory effect. LPS is a well-known endotoxin that initiates inflammatory responses. LPS binds to TLR4 and effects several adaptor proteins such as toll-IL-1 receptor domain-containing adaptor protein, TNFreceptor-activated factor 6 , and transforming growth factor $\beta$-activated kinase 1 . These receptor and adaptor proteins transmit signals to several pathways, such as nuclear factorkappa B (NF- $\kappa \mathrm{B})$, one of the key regulators of inflammation and mitogen-activated protein kinase (MAPK) signaling [30]. $\mathrm{NF}-\kappa \mathrm{B}$ signaling can be activated by various stimulators such as inflammatory cytokines, LPS, microorganisms, and ultraviolet light. Activated NF- $\kappa \mathrm{B}$ signaling induces an increase in the expression of proinflammatory cytokines and NO synthase [31]. MAPK signaling is also another major pathway involved in the inflammatory response. Transforming growth factor $\beta$-activated kinase 1 activates MAPK kinases, and they subsequently phosphorylate extracellular signal-regulated kinase, p38, and c-Jun N-terminal kinase. Moreover, phosphorylation of activator protein-1, ETS Like-1 protein Elk-1, and transcription factors initiate the transcription of inflammatory genes [32]. In the future, the effect of HEHSQ on NF- $\kappa$ B and MAPK signaling, which are the key mediators of inflammatory signaling, should be evaluated.

\section{Conclusions}

In conclusion, to the best of our knowledge, our study provides the first evidence that SQ decreases the inflammatory mediators NO, TNF- $\alpha$, and CCL2. Moreover, we also showed that the anti-inflammatory effects of HEHSQ are 100 times more potent than those of natural SQ. Our results in this study could be a great contribution to local pharmacological applications, mainly for the handicap of higher cell toxicity. The results presented here suggest that HEHSQ may be potentially used as a safe alternative treatment to anti-inflammatory drugs. Therefore, we recommend the consumption of foods containing SQ, such as shark liver oil and olive oil, because oral administration of SQ is well absorbed (60-85\%) in humans [32] and minimize the SQ solubility and bioavailability problems of several pharmacological activities.

\section{Abbreviations \\ CCL2: C-C motif chemokine 2 \\ cDNA: Complementary DNA}

LPS: $\quad$ Lipopolysaccharide

MAPK: Mitogen-activated protein kinase

MTT: 3-(4,5-Dimethylthiazol-2-yl)-2,5-

diphenyltetrazolium bromide

NF- $\kappa$ B: Nuclear factor-kappa B

NO: $\quad$ Nitric oxide

NSAIDs: Nonsteroidal anti-inflammatory drugs

TNF- $\alpha$ : Tumor necrosis factor- $\alpha$

TLR4: $\quad$ Toll-like receptor 4.

\section{Data Availability}

The data used to support the findings of this study are included within the article.

\section{Conflicts of Interest}

The authors declare that they have no conflicts of interest.

\section{Authors' Contributions}

KS and TA wrote the manuscript; YI, TA, and HK synthesized 2-(2-hydroxyethoxy)-3-hydroxysqualene; KS performed the in vitro experiments; KS, YI, and TA analyzed the data; and KS, KT, TA, HK, and HI planned the study. All authors read and approved the final manuscript.

\section{Acknowledgments}

This study was supported by the Japan Science and Technology-Japan International Cooperation Agency (JSTJICA)'s SATREPS Project "Valorization of Bio-resources in Semi-Arid and Arid Land for Regional Development" (JPMJSA1506).

\section{Supplementary Materials}

Supplementary figures provide data on the cytotoxic effects (Figure 1) and anti-inflammatory effects (Figure 2 and Figure 3) of DMSO as a vehicle. (Supplementary Materials)

\section{References}

[1] W.-J. Yoon, Y. M. Ham, S.-S. Kim et al., "Suppression of proinflammatory cytokines, iNOS, and COX-2 expression by brown algae Sargassum micracanthum in RAW 264.7 macrophages," EurAsian Journal of Biosciences, vol. 3, pp. 130143, 2009.

[2] Z.-S. Wen, X.-W. Xiang, H.-X. Jin et al., "Composition and anti-inflammatory effect of polysaccharides from Sargassum horneri in RAW264.7 macrophages," International Journal of Biological Macromolecules, vol. 88, pp. 403-413, 2016.

[3] J. M. Peter and A. W. Thomas, "Protective and pathogenic function of macrophage subsets," Nature Reviews Immunology, vol. 11, no. 11, pp. 723-737, 2011.

[4] D. L. Laskin and K. J. Pendino, "Macrophages and inflammatory mediators in tissue injury," Annual Review of Pharmacology and Toxicology, vol. 35, no. 1, pp. 655-677, 1995.

[5] S. Jie, Z. Xueji, B. Mark, and F. Harry, "Measurement of nitric oxide production in biological systems by using Griess reaction assay," Sensors, vol. 3, no. 8, pp. 276-284, 2003. 
[6] H. Osiecki, "The role of chronic inflammation in cardiovascular disease and its regulation by nutrients," Alternative Medicine Review, vol. 9, no. 1, pp. 32-53, 2004.

[7] J. C. Stoclet, B. Muller, R. Andriantsitohaina, and A. Kleschyov, "Overproduction of nitric oxide in pathophysiology of blood vessels," Biochemistry. Biokhimiia, vol. 63 , no. 7, pp. 826-832, 1998.

[8] K. Laing and C. J. Secombes, "Chemokines," Developmental \& Comparative Immunology, vol. 28, no. 5, pp. 443-460, 2004.

[9] C. A. Feghali and T. M. Wright, "Cytokines in acute and chronic inflammation," Frontiers in Bioscience: A Journal and Virtual Library, vol. 2, no. 4, pp. d12-d26, 1997.

[10] C. Sostres, C. J. Gargallo, M. T. Arroyo, and A. Lanas, "Adverse effects of non-steroidal anti-inflammatory drugs (NSAIDs, aspirin and coxibs) on upper gastrointestinal tract," Best Practice \& Research Clinical Gastroenterology, vol. 24, no. 2, pp. 121-132, 2010.

[11] K. Kaya, A. Nakazawa, H. Matsuura, D. Honda, I. Inouye, and M. M. Watanabe, "ThraustochytridAurantiochytriumsp. $18 \mathrm{~W}-13 \mathrm{a}$ accumulates high amounts of squalene," Bioscience, Biotechnology, and Biochemistry, vol. 75, no. 11, pp. 22462248, 2011.

[12] T. A. Miettinen and H. Vanhanen, "Serum concentration and metabolism of cholesterol during rapeseed oil and squalene feeding," The American Journal of Clinical Nutrition, vol. 59, no. 2, pp. 356-363, 1994.

[13] H. Gylling and T. A. Miettinen, "Postabsorptive metabolism of dietary squalene," Atherosclerosis, vol. 106, no. 2, pp. 169-178, 1994.

[14] Z.-R. Huang, Y.-K. Lin, and J.-Y. Fang, "Biological and pharmacological activities of squalene and related compounds: potential uses in cosmetic dermatology," Molecules, vol. 14, no. 1, pp. 540-554, 2009.

[15] T. Bosak, R. M. Losick, and A. Pearson, "A polycyclic terpenoid that alleviates oxidative stress," Proceedings of the National Academy of Sciences, vol. 105, no. 18, pp. 6725-6729, 2008.

[16] S. Takahashi, M. Sakamaki, F. Ferdousi et al., "Ethanol extract of Aurantiochytrium mangrovei 18W-13a strain possesses anti-inflammatory effects on murine macrophage RAW264.7 cells," Front Physiol, vol. 9, p. 1205, 2018.

[17] H. H. Rees, L. J. Goad, and T. W. Goodwin, "Cyclization of 2,3-oxidosqualene to cycloartenol in a cell-free system from higher plants," Tetrahedron Letters, vol. 9, no. 6, pp. 723-725, 1968.

[18] J. N. Sharma, A. Al-Omran, and S. S. Parvathy, "Role of nitric oxide in inflammatory diseases," Inflammopharmacology, vol. 15, no. 6, pp. 252-259, 2007.

[19] C. Bogdan, "Nitric oxide and the immune response," Nature Immunology, vol. 2, no. 10, pp. 907-916, 2001.

[20] M. Z. Jun and A. Jianxiong, "Cytokines, inflammation and pain," International Anesthesiology Clinics, vol. 45, no. 2, pp. 27-37, 2007.

[21] H. M. Storm, S. Y. Oh, B. F. Kimler, and S. Norton, "Radioprotection of mice by dietary squalene," Lipids, vol. 28, no. 6, pp. 555-559, 1993.

[22] G. S. Kelly, "Squalene and its clinical uses," Alternative Medicine Review, vol. 4, no. 1, pp. 29-36, 1999.

[23] Y. Aguilera, M. E. Dorado, F. A. Prada, J. J. Martínez, A. Quesada, and V. Ruiz-Gutiérrez, "The protective role of squalene in alcohol damage in the chick embryo retina," Experimental Eye Research, vol. 80, no. 4, pp. 535-543, 2005.

[24] J. Lee, N. Tae, J. J. Lee, T. Kim, and J. H. Lee, "Eupatolide inhibits lipopolysaccharide-induced COX-2 and iNOS expression in RAW264.7 cells by inducing proteasomal degradation of TRAF6," Eur J Pharmacol, vol. 636, no. 1-3, pp. 173-180, 2010.

[25] D. G. Arango and A. Descoteaux, "Macrophage cytokines: involvement in immunity and infectious diseases," Frontiers in Immunology, vol. 5, p. 491, 2014.

[26] I. F. Charo and R. M. Ransohoff, "The many roles of chemokines and chemokine receptors in inflammation," New England Journal of Medicine, vol. 354, no. 6, pp. 610-621, 2006.

[27] R. Gillitzer and M. Goebeler, "Chemokines in cutaneous wound healing," Journal of Leukocyte Biology, vol. 69, no. 4, pp. 513-521, 2001.

[28] A. B. Lentsch, "The duffy antigen/receptor for chemokines (DARC) and prostate cancer. a role as clear as black and white?" The FASEB Journal, vol. 16, no. 9, pp. 1093-1095, 2002.

[29] J. Lu, Y. Zhang, and J. Shi, "Effects of intracerebroventricular infusion of angiotensin-(1-7) on bradykinin formation and the kinin receptor expression after focal cerebral ischemiareperfusion in rats," Brain Research, vol. 1219, pp. 127-135, 2008.

[30] S. A. Schwartz, A. Hernandez, and B. Mark Evers, "The role of $\mathrm{NF}-\kappa \mathrm{B} / \mathrm{I} \kappa \mathrm{B}$ proteins in cancer: implications for novel treatment strategies," Surgical Oncology, vol. 8, no. 3, pp. 143-153, 1999.

[31] H. Hasturk, A. Kantarci, and T. E. Van Dyke, "Oral inflammatory diseases and systemic inflammation: role of the macrophage," Frontiers in Immunology, vol. 3, p. 118, 2012.

[32] N. Gohil, G. Bhattacharjee, K. Khambhati, D. Braddick, and V. Singh, "Engineering strategies in microorganisms for the enhanced production of squalene: advances, challenges and opportunities," Frontiers in Bioengineering and Biotechnology, vol. 7, p. 50, 2019. 